\title{
Utilization of produced condensate for enhanced oil recovery: a case study for the forest reserve field in Trinidad
}

\author{
Daron Lall $^{1} \cdot$ David Alexander $^{2} \cdot$ Rean Maharaj $^{3} \cdot$ Indar Narace $^{2} \cdot$ Mohammad Soroush $^{2}$
}

Received: 20 August 2020 / Accepted: 21 December 2020 / Published online: 12 January 2021

(c) The Author(s) 2021

\begin{abstract}
The current global economic trends of low commodity prices for hydrocarbons, competition due to the emergence of shale oil and gas, as well as the decline in production from mature oilfields in Trinidad and Tobago (TT) have fuelled the need for the implementation of efficient and enhanced oil recovery methods. Of particular concern locally is the issue of decreasing oil production and increasing production costs in mature oil fields due to the prevalence of organic deposits (paraffin or asphaltenes), which results in the coating of production tubing causing the plugging of surface equipment, pipelines, perforations and pore spaces in the geological formation. Major deposition compound paraffins and asphaltene are soluble in condensate, which is relatively cheap and is produced as a by-product and flared in TT, and it is already used as a pipeline diluent and cleaner for deposits. The strategy of utilizing this "waste" solvent as an economical and environmentally friendly strategy for EOR was worth investigation. The FR 1346 RD well was selected for evaluation, and a pilot test was conducted using the compositional reservoir simulation model (CMG-GEM). Laboratory studies were conducted using a constructed pressure permeability flow chamber, and results from the device indicated that an asphaltene plug decreased the permeability by approximately $24 \%$, but after treatment with condensate, there was an improvement in permeability of approximately $10 \%$ (300 md to $420 \mathrm{md}$ ). Tuning of the simulation model incorporating the laboratory-derived permeability data resulted in an increase in production rate to 35 bopd, which matched very closely with the field pilot well test result of an increase of $46 \%$ (from 20 to 39 bopd) when the condensate soak was performed. This increase translated in an overall gain of 30,531 bbls of oil associated with a financial gain of approximately $\$ 4.7 \mathrm{MM}$ TT per well over the 16-year period. Injection types including condensate, carbon dioxide and nitrogen yielded the production of the same order. This study offers compelling evidence that the use of produced condensate in EOR is an economically and environmentally friendly strategy in TT.
\end{abstract}

Keywords Condensate $\cdot$ EOR $\cdot$ Asphaltenes $\cdot$ Paraffins $\cdot$ Permeability

\section{Introduction}

The economy of Trinidad and Tobago (TT) heavily depends on the petroleum industry; however, this narrative is being forced to change due to the current global economic trend of falling oil and gas prices, increasing competition due to the monetization of huge international reserves of shale oil

Rean Maharaj

rean.maharaj@utt.edu.tt

1 Master of Science in Reservoir Engineering, University of Trinidad and Tobago, Point Lisas, Trinidad and Tobago

2 Energy Systems Engineering Unit, University of Trinidad and Tobago, Point Lisas, Trinidad and Tobago

3 Process Engineering Unit, University of Trinidad and Tobago, Point Lisas, Trinidad and Tobago and gas, as well as the maturation of local oilfields (Cifarelli, Wagner and Marchionna. 2018; Conrad and Jagessar. 2018) One of the significant challenges in TT with regard to oil production is the low recovery factor $(\mathrm{RF})$ associated with its mature oilfields as, in many cases, oil production has peaked and/or is in a state of decline. Oil-producing companies are now focussed on maximizing the recovery factors of their oil fields and maintaining an economic oil rate. The improved oil recovery (IOR) involves improving oil recovery by any means practically possible and can include secondary oil recovery and enhanced oil recovery (EOR) processes.

The use of enhanced oil recovery (EOR) strategies is specifically applicable to the heavy oil reserves located in South West Trinidad where it is estimated that it contains in excess of 1 billion barrels of oil in place (OIP) (Hosein et al. 2011; Sinanan et al. 2016). EOR refers to the recovery of oil

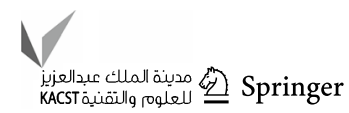


through the injection of fluids and energy not normally present in the reservoir. As described by Romero-Zeron. (2012), these injected fluids facilitate the EOR process as they can boost the natural energy in the reservoir, interact with the reservoir rock/oil system to create conditions favourable for residual oil recovery, reduce the interfacial tension between the displacing fluid and oil, increase the capillary number, reduce capillary forces, increase the drive water viscosity, provide mobility control, facilitate oil swelling, reduce oil viscosity and improve reservoir rock wettability characteristics. The ultimate goal of EOR processes is to increase the overall oil displacement efficiency. The overall displacement efficiency of any oil recovery displacement process can be increased by improving the mobility ratio or by increasing the capillary number or both. The oil sector in TT has produced over $320 \mathrm{MMbbls}$ of oil via several conventional secondary and EOR processes (Sinanan et al. 2016). The techniques used currently include WASP, steam flood and water flood with fourteen (14) operational projects on stream as of 2017 (Ministry of Energy and Energy Industries. 2019).

Apart from the issue of decreased oil production associated with the mature fields, there is a prevalence of organic deposits (paraffin or asphaltenes), which results in the coating of production tubing resulting in the plugging surface equipment, pipelines, perforations and pore spaces in the geological formation. The extent of plugging is shown in Fig. 1, which depicts the cross section of tubing used in oil production with $90 \%$ degree of asphaltene waxing present.

The restriction of flow in these pipings due to these deposits can greatly reduce a well's production rate compared its potential production rate (Boswood et al. 2011). Crude oil in its natural state in the reservoir is in a state of equilibrium, and materials such as paraffins and asphaltenes are in solution; however, when the crude is extracted, this equilibrium is disturbed by a drop in pressure and temperature below the cloud point and precipitation of organic material can occur.

In recent years, solvent addition primarily utilizing hydrocarbon condensate ( $\mathrm{C} 4$ to $\mathrm{C} 20$ ) to steam operations (such as CSS and SAGD) has developed as a potential strategy to

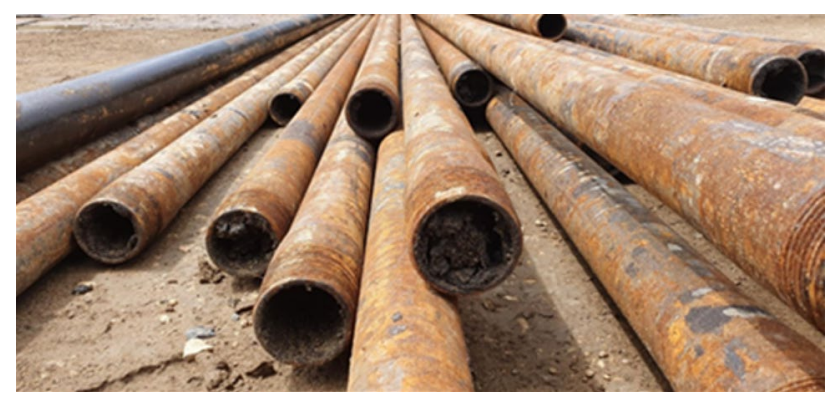

Fig. 1 Cross section of a 90\% waxed tubing (Picture courtesy Lease Operators Limited) improve not only oil recovery and energy efficiency in heavy oil and bitumen reservoirs but has been shown to be useful in mitigation of deposition issues (Hedden et al. 2015). The strategy of solvent addition to a steam drive process has been employed by Shell in the Peace River area in Canada and has had successes of oil uplift in the patterns where solvent was injected. A strategy of a 4-month concentrated slug of solvent in two steam drive patterns produced a significant production uplift when compared to steam-only injections of neighbouring patterns. The use of solvent injection methods such as vapour extraction (VAPEX) and cyclic solvent injection (CSI) has been used to extract heavy oil or bitumen deposits. The mechanism of action involves the injected solvent being dissolved into the heavy oil, resulting in a reduction of the oil viscosity, the occurrence of in situ deasphaltening and the ability of production of the diluted oil by gravity drainage or pressure depletion (Ivory et al. 2010). Studies conducted suggest that the VAPEX strategy process is useful for recovering thin reservoirs (Butler and Jiang 2000; Knorr and Imran 2011). The solvent huff-n-puff process or CSI process basically consists of an injection cycle, a soaking period and a production cycle (Ivory et al.2010; Jamaloei et al. 2012). An enhanced solvent injection EOR technique for heavy oil, cyclic production with continuous solvent injection (CPCSI) was evaluated by Liu et al. (2017). The study utilized various sand-pack models saturated with a Western Canada heavy oil sample. The effect of solvent treatment on the pressure drop through the physical model was measured using a digital pressure transducer, and the changes in the permeability of the sand-pack model were determined by applying the Darcy's law for steady-state fluid flow using 1D and 2D sand-packed physical models. The results suggest that the recovery factors can improve as much as $11 \%$ using this technique.

As presented by Sinanan et al. (2016), a comprehensive review of the IOR techniques adopted in Trinidad suggested that IOR projects have the potential of increasing crude oil production by up to $15 \%$. The adoption of a "Trinidad Specific" screening criteria is critical to the success of IOR strategies. The use of solvents such as condensate for deasphaltening is not currently being used in TT, and there exists limited information via research studies for its application locally. Apart from being successful in other territories, its feasibility is worth investigation as TT produces approximately 9000 bopd equivalent of condensate most of which is flared (Ministry of Energy and Energy Industries 2019). Since the major deposition compounds such as paraffins and asphaltene are soluble in condensate, it is intuitive to believe that condensate can be used as an economical and environmentally friendly strategy for EOR. Produced condensate can form distillable oil banks for miscible displacement and is a cheap solvent, which is already used locally as a pipeline diluent for transporting crude and to assist in the cleaning 
of tubulars and flow lines eliminating operating cost and regular rig work. This paper investigates the feasibility using condensate for EOR in a mature reservoir in TT. The overall methodology to accomplish the objectives required involves the following steps: selection of the appropriate well, developing a pilot test using compositional reservoir simulation model (CMG-GEM) and finally conducting an economic analysis of the strategy. Well selection, the pilot test development and economic analysis of the strategy will be conducted using reservoir and other data for candidate wells provided by Lease Operators Limited. Due to the uncertainty in permeability data required for the modelling of the reservoir, the laboratory determination of permeability changes in asphaltene-infused wells due to treatment with condensate will have to be conducted in order to fill this information gap. The incorporation of permeability data derived in the laboratory within the simulation model will allow for the tuning of the simulation model to generate more realistic and accurate projections and evaluations of the strategy.

\section{Methodology}

The economic analysis was done to analyse savings associated with a condensate treatment extended over the life of the well. The analysis was conducted on one well with the asphaltene-plugging problem; the results of which can be multiplied by the number of wells across a field to estimate the cost of the entire field. The data for associated steam cleaning costs, winch costs and condensate costs were obtained from Lease Operators Limited. The condensate treatment process involved a monthly condensate soak using 25 bbls of condensate (@ $\$ 60$ tt per barrel), and the costs and prices were extended over the next 16 years. The exchange rate used was $\$ 7.00 \mathrm{TT}$ to $\$ 1.00$ US.

The methodology for the selection of the appropriate well for this investigation involves comparing the reservoir data for candidate wells, which was provided by Lease Operators Limited and is shown in Table 1 to the EOR screening parameters as prescribed by Taber et al. (1997) and Sheng (2015).

The pilot test simulation model was developed using the field data presented in Table 1 for the Well-FR 1346 $\mathrm{RD}$ along with the radial grid model as seen in Fig. 2 as inputs for the commercial software like Computer Modelling Group Limited software (CMG-GEM).

The model was created to be 10 grid blocks in the $i$ direction, 1 block in the $\mathrm{j}$ direction and 8 blocks in the $k$ direction with each block being varying in size to represent an area of $13,669.93$ acres-feet. The drainage radius was $1200 \mathrm{ft}$, the thickness was $64 \mathrm{ft}$, the average permeability throughout the reservoir was $300 \mathrm{mD}$ and the water saturation was $35 \%$. The deposited substance (asphaltene and wax) is modelled
Table 1 Reservoir data for selected wells (courtesy Lease Operators Limited)

\begin{tabular}{lll}
\hline Oil properties. well - FR 1346 RD & & \\
\hline Oil gravity & $\mathrm{API}$ & 23.9 \\
Oil viscosity & $\mathrm{cP}$ & $\mathrm{tbt}$ \\
Reservoir characteristics & & \\
Formation type & Sandstone & Sandstone \\
Formation name & - & Coora Sand \\
Saturation & $\%$ & 0.6 \\
Average net pay & $\mathrm{ft}$ & 64 \\
Average permeability & $\mathrm{mD}$ & 200 \\
Average depth & $\mathrm{ft}$ & - \\
Temperature & $\mathrm{F}$ & 138 \\
Avg. porosity & - & 0.3 \\
Initial pressure & Psi & 2200 \\
Initial production on pump & bopd & 40 \\
Present pressure & Psi & 300 \\
Present production & bopd & 29 \\
\hline
\end{tabular}

as a pure solid, and the composition of the reservoir fluid (black oil with asphaltene and wax) used in the simulation is shown in Table 2. The black oil with asphaltene and wax model produced the best decline match, and hence, this fluid model was used in the analysis.

The model presented is for the description of asphaltene precipitated and deposited over constant temperature, with variations of pressure and fluid compositions. A slug of condensate $1123 \mathrm{ft}^{3} /$ day for 6 days was injected as per the field pilot project. For comparison, it was also injected with a slug of carbon dioxide and a slug nitrogen $100,000 \mathrm{ft}^{3} /$ days for 6 days. The simulation was run until 2035.

The effect of condensate treatment on the changes in the permeability of the sand-pack model was determined by applying the Darcy's law for steady-state fluid flow as described by Liu et al. (2017). A pressure permeability flow chamber was constructed in the laboratory for this purpose, and the design is shown in Fig. 3.

The device constructed is basically a modified version of a core testing chamber and utilizes the Darcy's equation whereby the permeability of the porous medium can be calculated using Eq. 1 as described by (Masoodi and Pillai. 2011; Liu et al. (2017):

$Q=-\frac{k A\left(p_{b}-p_{a}\right)}{\mu L}$

where the rate of production in $\mathrm{Q}$ is related to the viscosity, $(\mu)$, the permeability $(k)$, the cross-sectional area $(A)$, the total pressure drop $\left(\mathrm{p}_{\mathrm{b}}-\mathrm{p}_{\mathrm{a}}\right)$ and the length of the sample $(L)$.

The purpose of this device is to measure the increasing effect on the permeability of the sand-packed models due to

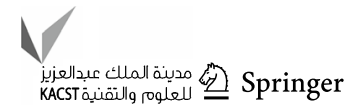




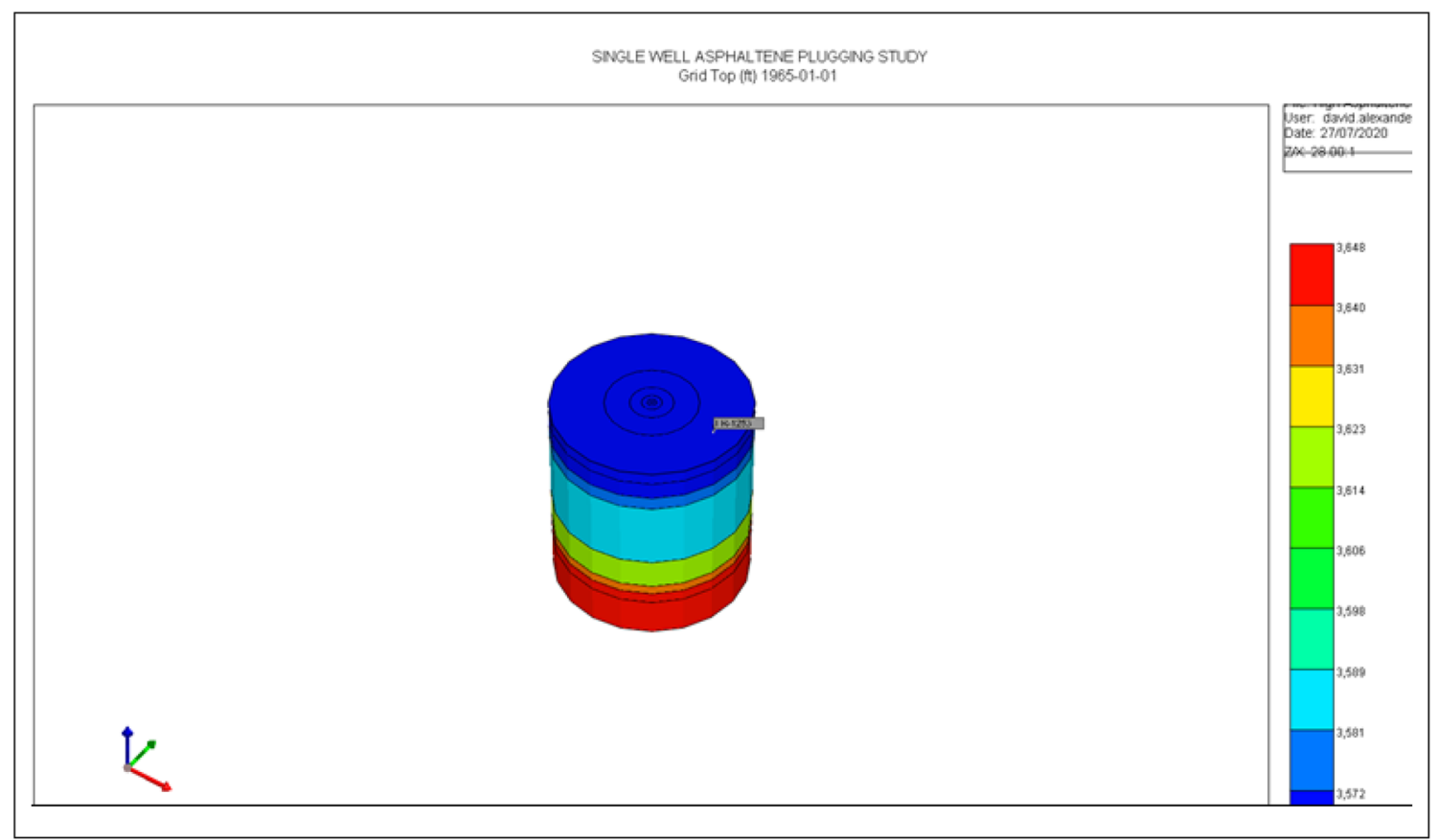

Fig. 2 Areal view of the single-well radial grid model use in the pilot test simulation

Table 2 Composition of the black oil with asphaltene and wax reservoir fluid

\begin{tabular}{lc}
\hline Component & \% Composition \\
\hline $\mathrm{CO} 2$ & 2.459999993 \\
$\mathrm{~N} 2$ & 0.569999998 \\
$\mathrm{C} 1$ & 36.36999989 \\
$\mathrm{C} 2$ & 3.46999999 \\
$\mathrm{C} 3$ & 4.049999988 \\
$\mathrm{IC} 4$ & 0.589999998 \\
$\mathrm{NC} 4$ & 1.339999996 \\
$\mathrm{IC} 5$ & 0.739999998 \\
$\mathrm{NC} 5$ & 0.829999998 \\
$\mathrm{FC} 6$ & 1.619999995 \\
$\mathrm{C} 07-\mathrm{C} 15$ & 19.65888694 \\
$\mathrm{C} 16-\mathrm{C} 25$ & 12.55131396 \\
$\mathrm{C} 26-\mathrm{C} 30$ & 4.000532288 \\
$\mathrm{C} 31 \mathrm{~A}+$ & 7.424659978 \\
$\mathrm{C} 31 \mathrm{~B}+$ & 4.324606987 \\
\hline
\end{tabular}

\section{Results}

the presence of asphaltenes in a sand-packed porous medium as well as to measure the possible decreasing effect on the permeability of the asphaltene-containing sand-packed porous medium after a condensate soak. To achieve this, a control model was prepared where the chamber was packed with clean sand as the porous medium. Water was allowed to flow through the sand for one minute and the permeability of the control system calculated using the Darcy's equation. To investigate the effect of the asphaltenes on the permeability of the sand-packed porous media, the chamber was then repacked with fresh porous medium modified with asphaltene (10\% wt. of sand). The water was allowed to flow through the system and the permeability calculated. To measure the reduction in permeability of the asphaltenemodified sand-packed porous medium due to condensate treatment, the chamber containing the packing material was then soaked with condensate for $6 \mathrm{~h}$ after which the permeability test was redone and the resulting permeability after the condensate soak was then calculated. The laboratoryderived values of permeability for the different scenarios were used as input values in the numerical modelling and simulation protocol to generate more realistic projections. This was done by replacing the permeability value in the reservoir section of the static model, hence accounting for the impact of asphaltene precipitation during the production phase.

\section{Well selection}

\section{Field location}

As shown in Fig. 4, the fields of interest are located in the southern area of Trinidad, and further descriptions are represented in Fig. 5 and Fig. 6.

The area of interest for this study is found within the Coora Sands in Forest Reserve Area of Trinidad, and these 


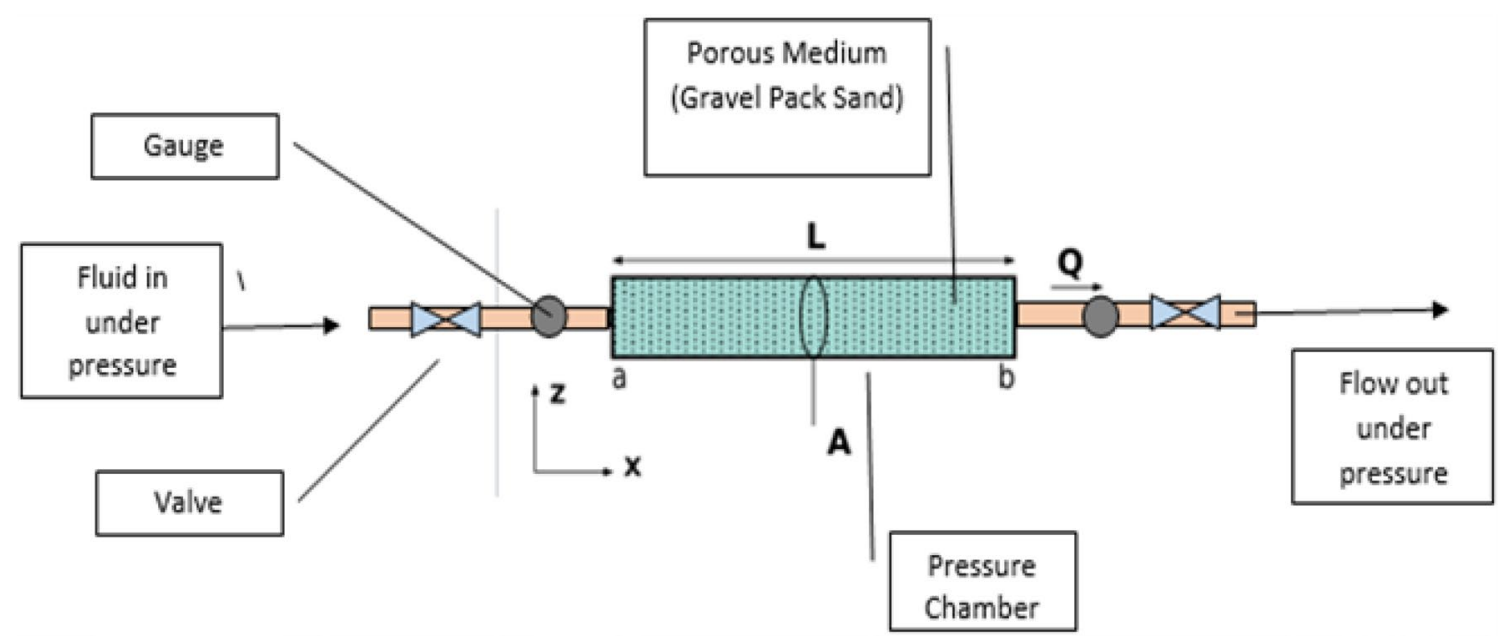

Fig. 3 Pressure permeability flow chamber apparatus constructed for the study

Fig. 4 Location of Trinidad's heavy oil fields of interest

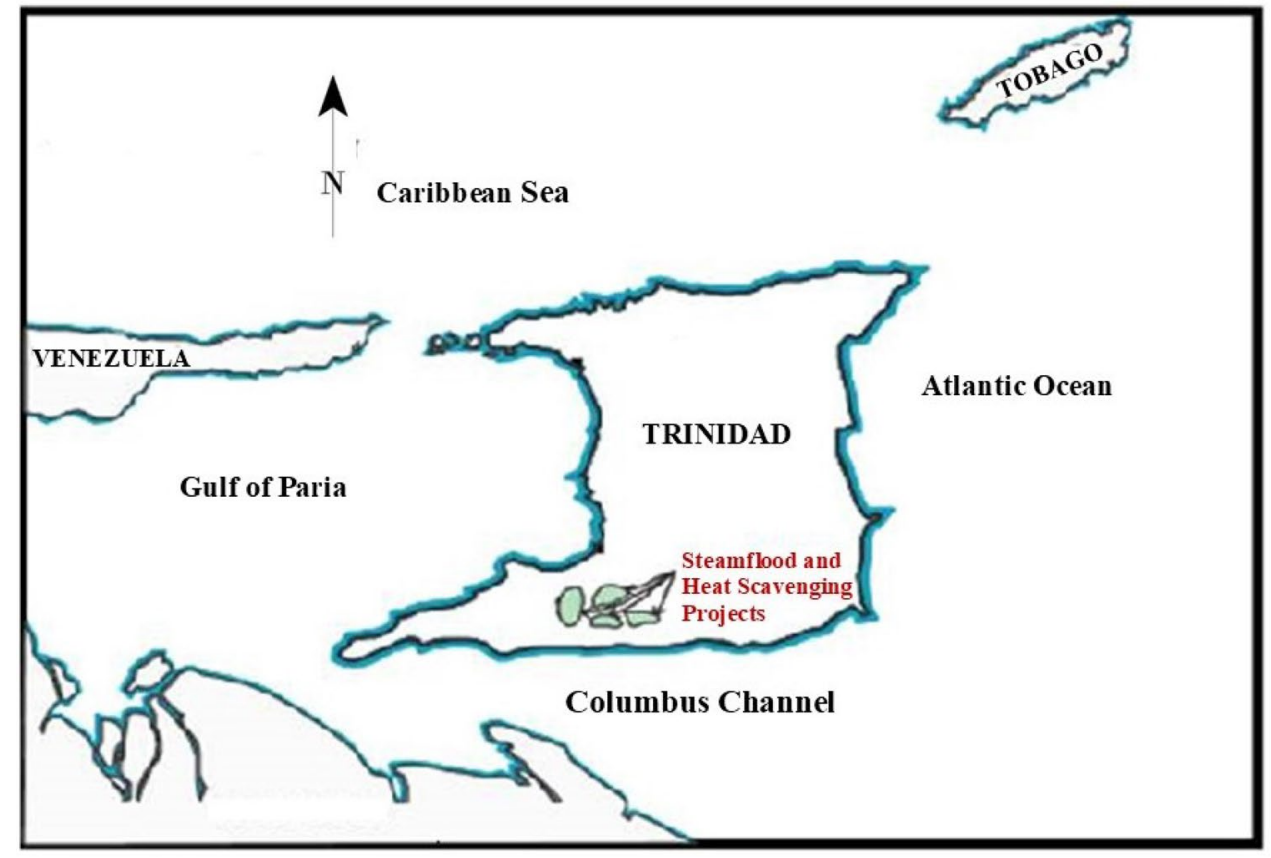

are trending Northern Boundary Fault and a NW-SE-trending synthetic splay with approximately $100^{\prime}$ of reverse displacement. The sand package dips at an angle of $55^{\circ}$ to the north-northeast and is relatively continuous throughout the block. Faulting serves as the primary trapping mechanism for hydrocarbons in this area.

\section{Screening criteria}

The unique characteristics of reservoir parameters and fluid properties are critical for the selection and success of an EOR strategy The FR 1346 RD was selected to evaluate the feasibility of using condensate for EOR as it met the general screening criteria for this type of EOR. The reservoir data for candidate wells were provided by Lease Operators Limited, and they were compared to the stipulated screening parameters as described by Taber et al. (1997) and Sheng (2015).

The FR-1346RD was spudded on 6 February 2010. The well was kicked off at 417'and was drilled generally trouble-free to a total depth of $3830^{\prime}$ with a maximum mud density of 81 pcf. The $5 \frac{1 / 2}{2}$, casing shoe was landed at $3825^{\prime}$ with the baffle at 3786'. The well was perforated across the Coora Sand (Morne L'Fer) in the following intervals using 3 3/8" TCP Guns DP charges with 6 spf at 60 degree phasing. The well produced over 8 years with a 
Fig. 5 Heavy oil fields of interest for test wells selection in forest reserve
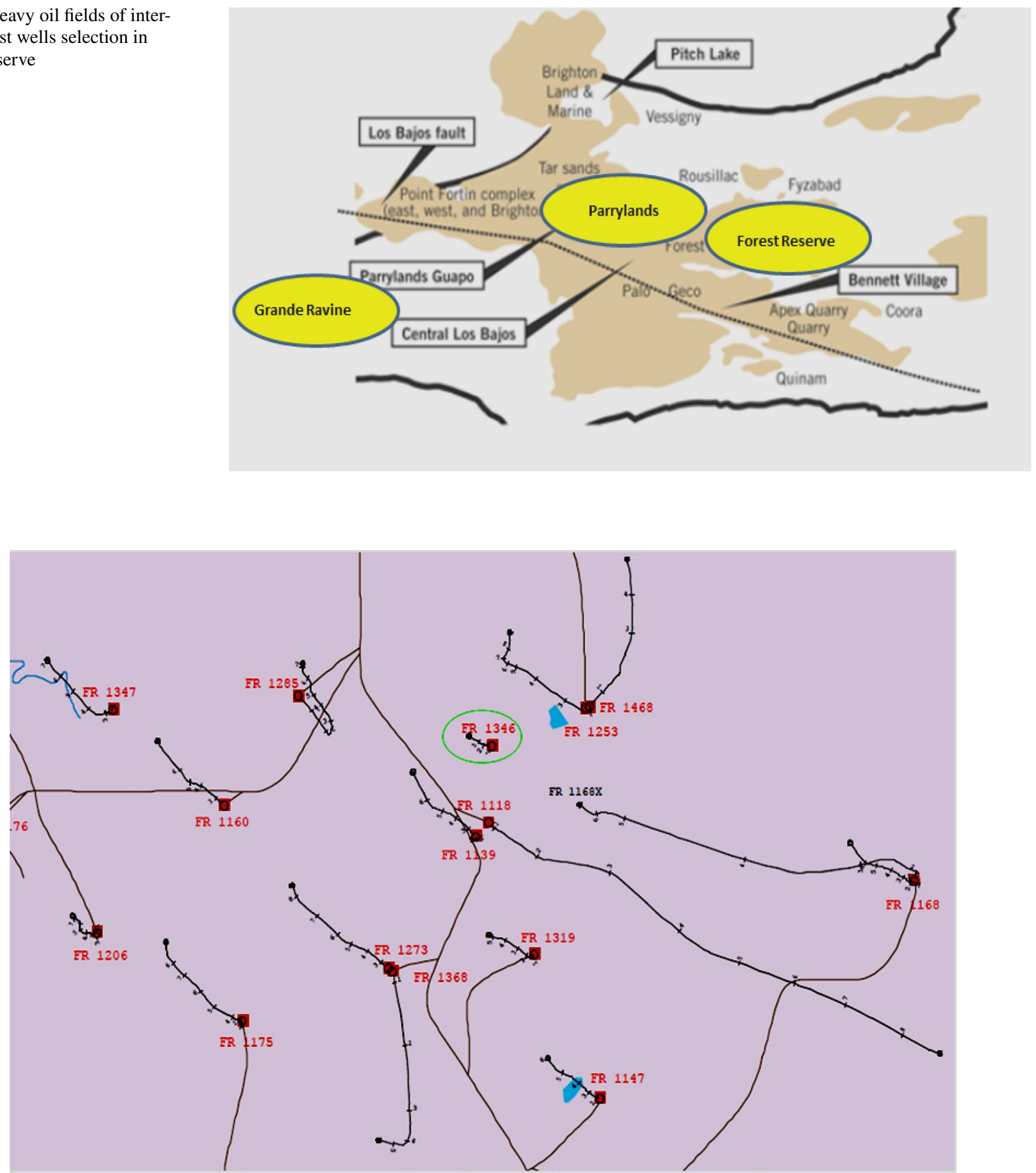

Fig. 6 Base map of forest reserve area of interest courtesy Lease Operators Limited

gradual decline but needed an average of 2 regular works over per year for tubing dewaxing. In December 2018, the well pumped off, the fluid level was just above the seating nipple and no inflow could be seen. This was due to suspected plugged perforations. The oil from the Morne L'Fer zone is 23.9 api, which is on the boarder of Heavy and Medium Oil.

\section{Numerical modelling results from pilot test of FR 1346 RD}

Pressure depletion plays a significant role in precipitation and deposition of asphaltene and wax in a reservoir particularly near the well bore, in the well bore and in production tubing. For example, when Well-FR 1346 RD was pumped off to the SN at $3380 \mathrm{ft}$, no inflow was seen in the well. The 
production was deemed to be zero or to slow for the well to be economical. The perforation was then soaked with $25 \mathrm{bbls}$ condensate for $24 \mathrm{~h}$. The fluid levels increased and the inflow improved, and the well was put to pump subsequently and production was monitored. From the results, an economic analysis was conducted into the impact of condensate. The FR 1346 RD well was pumped off and verification made of no apparent inflow. The waxed tubing in the well was replaced with clean tubing, SN depth of $3380 \mathrm{ft}$. and a new pump, and rods were installed. The well was then soaked for $24 \mathrm{~h}$ with the condensate; the performance of the well and the effect of the changes can be seen from the decline curves shown in Fig. 7.

Fluid levels were taken over a 2 -week period to monitor the inflow against the stabilized pump rates to monitor the performance of injecting the condensate. From the decline curves, subsequent to the injection of the condensate injected in December 2018, production returned to similar levels of performance prior waxing and a higher cumulative oil production was observed at the end of 2019.

\section{Simulation modelling}

For the simulation, the deposited asphaltene was modelled as a pure solid. Five (5) fluid models were utilized, and the characteristics and compositions are shown in Table 3.

The models presented are for the description of asphaltene precipitated and deposited over constant temperature with variations of pressure and fluid compositions. This allowed for a comparison of the effects of the condensate on performance using other known injection fluids. A slug of condensate $1123 \mathrm{ft}^{3} /$ day for 6 days was injected as per the field pilot project. For comparison, it was also injected with a slug of carbon dioxide and a slug nitrogen $100,000 \mathrm{ft}^{3} /$ days for 6 days. The simulation was run until 2035. Table 4 shows a comparison of the simulation

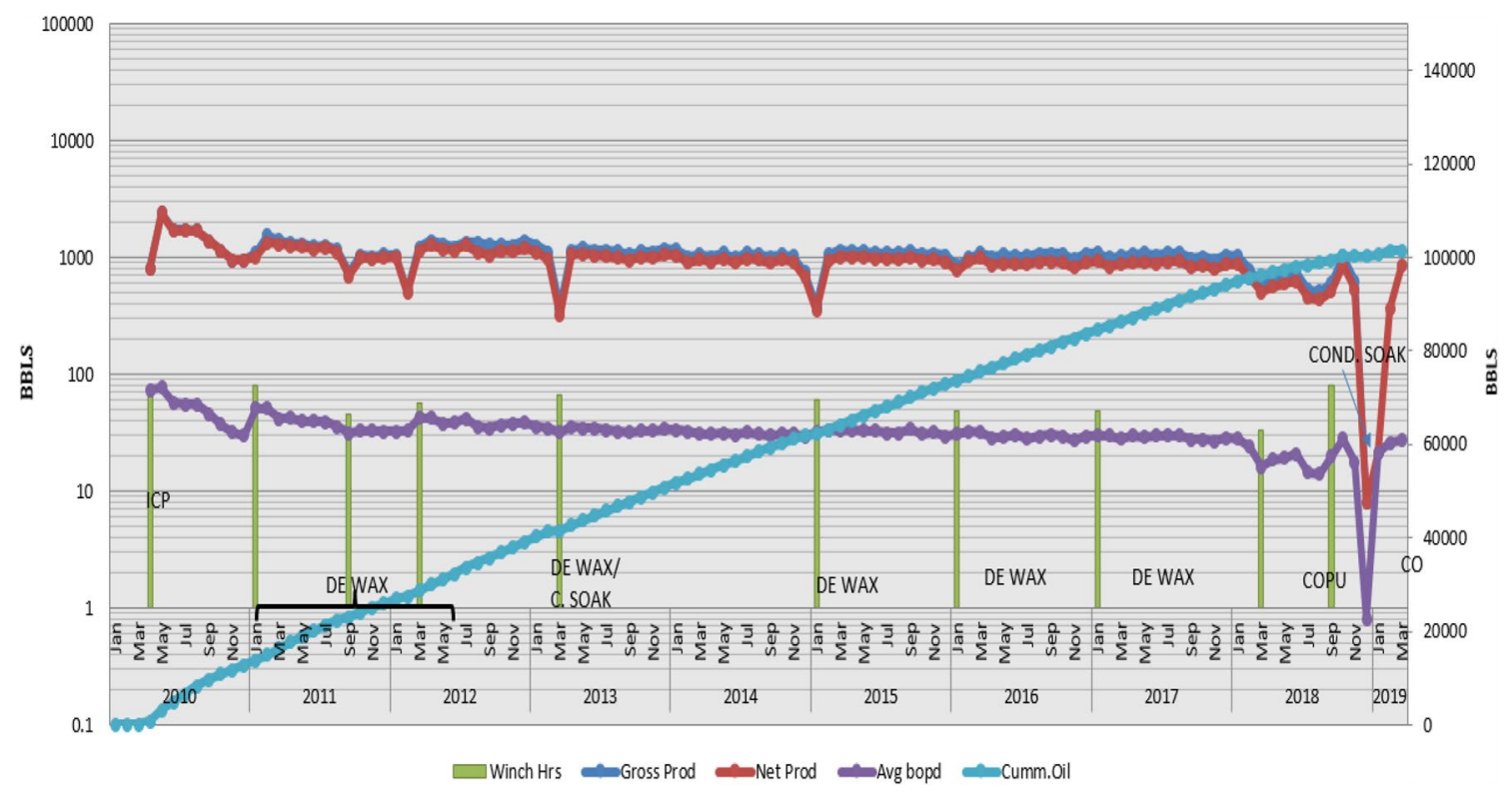

Fig. 7 Decline curves of FR 1346 RD (courtesy Lease Operators Limited)

Table 3 Fluid models and their associated characteristics and compositions used in the simulations

\begin{tabular}{|c|c|c|c|c|c|c|c|}
\hline Fluid models & $\begin{array}{l}\text { Saturation } \\
\text { pressure, } \\
\text { psia }\end{array}$ & Binary & $\begin{array}{l}\text { Molar vol } \\
\text { (L/Mol) }\end{array}$ & $\begin{array}{l}\text { Percentage } \\
\text { of } \mathrm{C} 31+\end{array}$ & $\begin{array}{l}\text { Percentage } \\
\text { of C31A }\end{array}$ & $\begin{array}{l}\text { Percentage } \\
\text { of C31B }\end{array}$ & $\begin{array}{l}\text { Switch } \\
\text { of } \\
\text { C31A } \\
\text { and } \\
\text { C31B }\end{array}$ \\
\hline Initial base black oil & 2200 & - & - & 11.749 & - & - & - \\
\hline Second asphaltene model & 1200 & 0.224 & 0.75 & - & 7.237 & 4.328 & - \\
\hline High solid asphaltene weight percent & 3000 & 0.3 & 0.75 & - & 12.914 & 20.063 & - \\
\hline C31A_C31B component switch & 2200 & 0.3 & 0.75 & - & 4.328 & 7.237 & $\sqrt{ }$ \\
\hline Main asphaltene fluid model & 2200 & 0.3 & 0.9 & - & 7.425 & 4.324 & $\sqrt{ }$ \\
\hline
\end{tabular}


Table 4 A comparison of the simulation results for the various injection-type case studies

Cumulative barrels for different injection types

\begin{tabular}{llll}
\hline No injection & Carbon dioxide & Nitrogen & Condensate \\
\hline 203,891 & 207,388 & 206,292 & 203,910 \\
\hline
\end{tabular}

results for the four case studies of different injection types for the black oil with asphaltene and wax.

The simulation results show that the cumulative barrels produced for all injection types were of the same order. Near-well bore asphaltene deposit was seen only when FR 1346 RD produced, drawing the pressure down allowing the solid asphaltene and wax to be deposited. From the simulation, no permanent impact was seen deep into the reservoir; however, from 0 to 10 feet some skin/deposits could be seen. History matching was conducted where the decline curves of each of the five models were compared to the natural decline of the well, the results of which are graphically shown in Fig. 8.

The results show that the black oil with asphaltene and wax had the best matching decline trend compared to the history-matched data. The black oil with asphaltene and wax fluid model was therefore selected to generate the required data for the radial model, and the results generated are detailed in Table 5.
Table 5 Radial model data obtained for the black oil with asphaltene and wax fluid model

Radial model data

Drainage radius $(\mathrm{ft})$

1200

Height(ft)

64

No.of radial grid blocks

10

No.of vertical grid blocks

8

Porosity $(\%)$

30

Horizontal perme ability(md) $\quad 300$

Vertical permeability(md) $\quad 300$

Water saturation(\%) $\quad 35$

Initial pressure(psia) $\quad 2200$

Temperture(F)

138

\section{Laboratory test (pressure permeability flow chamber results)}

The laboratory measurements of permeability were conducted using a sand-packed flow chamber constructed in the laboratory. The calculation of permeability was done by applying the Darcy's law for steady-state fluid flow as described by Liu et al. (2017). Sand-packed models of pure water through clean sand (the control), asphaltene-modified sand and asphaltene-modified sand utilizing a 6-h soak treatment with condensate were developed. Changes in permeability as a result of the condensate soak treatment

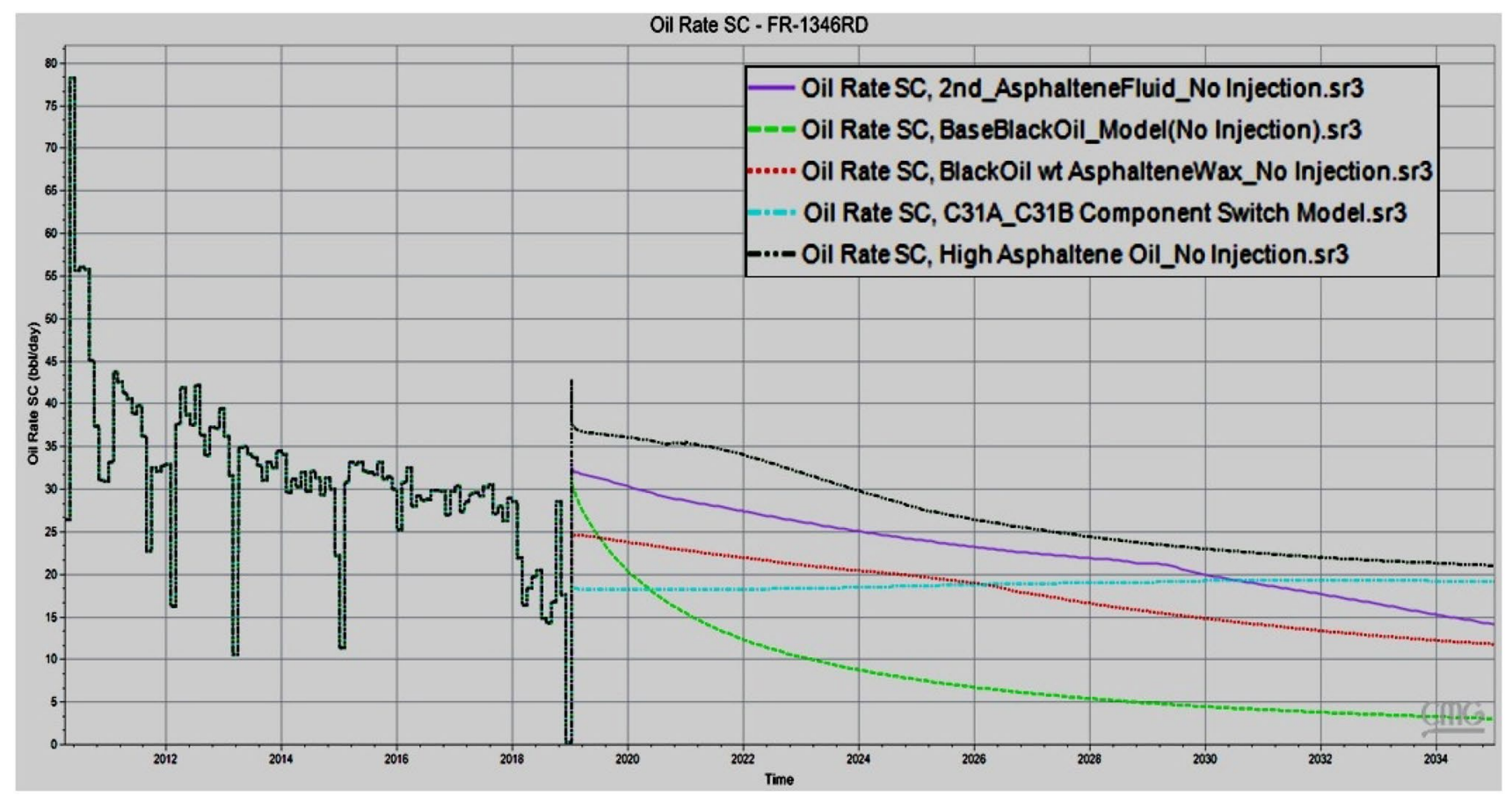

Fig. 8 History matching and decline curve analysis of the various fluid models 
from the laboratory measurements were used to modify the numerical model. The results of the permeability calculations, corresponding relative percentages and their correlation to the numerical model for the various scenarios at a pressure of $40 \mathrm{psig}$ for $1 \mathrm{~min}$ are shown in Table 6.

The results show that the introduction of the asphaltene plug resulted in a decrease in the permeability by approximately $24 \%$ of the value obtained with the clean packed sand. After treatment of the asphaltene plugged packed sand with the condensate, an increase in permeability from 300 to $420 \mathrm{md}$ (representing a $10 \%$ increase in permeability compared to the control) due to condensate treatment was recorded. Figure 9 shows a picture of a cross section of the chamber showing condensate soaked plugged packed sand after testing. It is noteworthy that the increase in permeability which influenced the increase in the daily production rate to 35 bopd matches very closely with the field pilot well test, which had an increase from 20 to 39 bopd when the condensate soak was performed.

The $10 \%$ improvement value in permeability from 23.8 to $33.3 \%$ (referenced to the control model) due to condensate treatment was incorporated to the numerical model in order to fine-tune and compensate for the effect of the condensate treatment. These percentages were back-worked into the simulation model to get an increase from 300 to 420 md permeability.

Figures 10 and 11 depict the simulated oil rate changes and cumulated oil production changes for FR 1346 RD due to increase in permeability from 300 to $420 \mathrm{md}$ as a result of the condensate treatment for the radial model after the tuning procedure.

As can be seen in Fig. 10, which shows the simulated oil rate changes for FR 1346 RD due to increase in permeability from 300 to $420 \mathrm{md}$ due to condensate treatment, the revised model predicted that an increase in the permeability will result in an increase in the rate of production of almost $46 \%$ as it improves from 24 to 35 bopd. The resulting cumulative production increases by $15 \%$ (approximately 30,531 barrels of oil) as can be seen from Fig. 11, which shows the simulated cumulated oil production changes for FR 1346 RD. As detailed in Table 7, recovery factors also improved when the condensate treatment was conducted and brought the well back on production from 7.69 to $15.71 \%$. This further improved to $18.06 \%$ when the

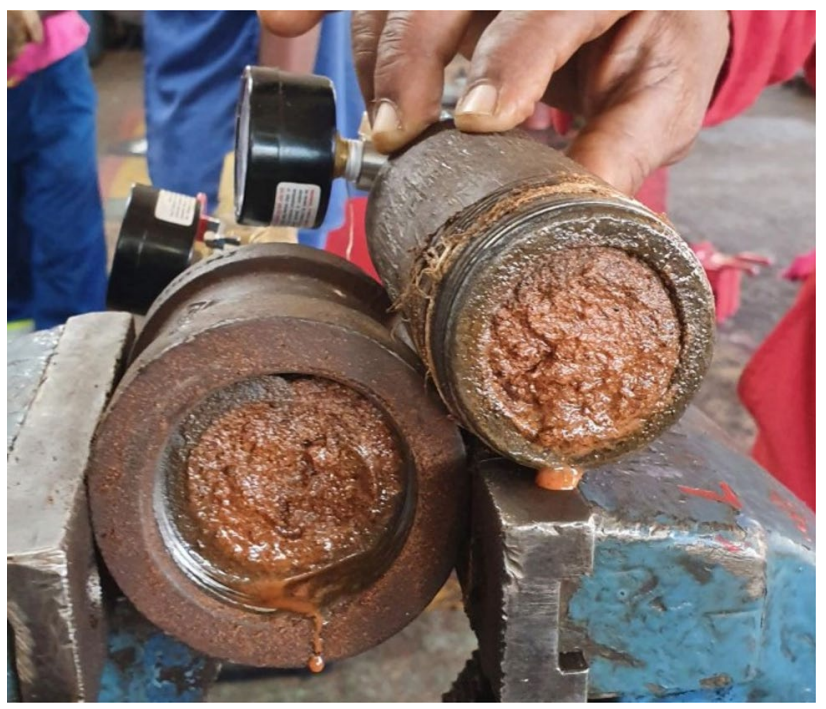

Fig. 9 Cross-sectional view of the chamber containing condensate soaked plugged packed sand after testing

permeability was changed from 300 to $420 \mathrm{md}$ due to the influence of the condensate.

\section{Economic analysis of the pilot test using Well-FR 1346 RD}

The economic analysis utilized data for material and other costs and was obtained from Lease Operators Limited. Table 8 shows the calculation of total cost associated with the use of steam cleaning for a 1-year period, and the value was found to be $\$ 132,336.00$. This estimated value was based on the winch costs and the steam cleaning process cost for the tubing associated with the process.

The condensate soak treatment process cost was $\$ 18,000$ ( 25 bbls of condensate @60 ttd per barrel),which resulted in an improved production after treatment with condensate of approximately 30,531 barrels of oil.

An economic evaluation associated with the use of the condensate treatment for an 16-year period is shown in Table 9. The estimation involved adding the cost savings associated with the condensation soak procedure with the additional revenue associated with the increased production due to implementation of a condensate soak (assuming an overall gain of 30,531 bbls of oil). The results show
Table 6 Measured permeability values for the different sandpacked models

\begin{tabular}{llll}
\hline Test & Permeability (K) & $\begin{array}{l}\text { Comparative } \\
\text { percentage }\end{array}$ & $\begin{array}{l}\text { Scaled to numerical } \\
\text { model permeability (k) } \\
\text { md units }\end{array}$ \\
\hline Packed sand & $3.54081 \mathrm{E}-12$ & 100 & 1260 \\
Packed sand with asphaltene plug & $8.43051 \mathrm{E}-13$ & 23.81 & 300 \\
$\begin{array}{l}\text { Condensate soaked packed sand with } \\
\text { asphaltene plug }\end{array}$ & $1.18027 \mathrm{E}-12$ & 33.33 & 420 \\
\hline
\end{tabular}




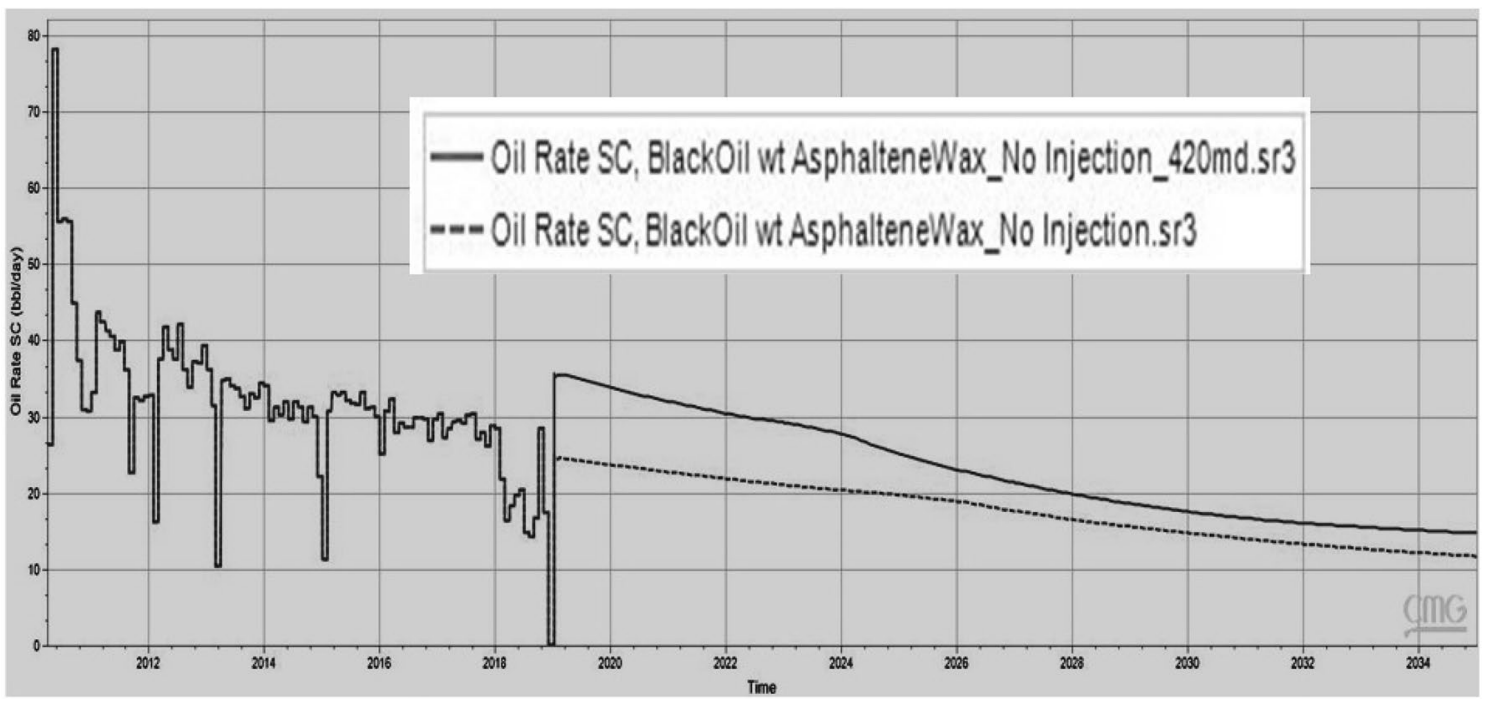

Fig. 10 Simulated oil rate changes for FR 1346 RD due to increase in permeability from 300 to 420 md due to condensate treatment

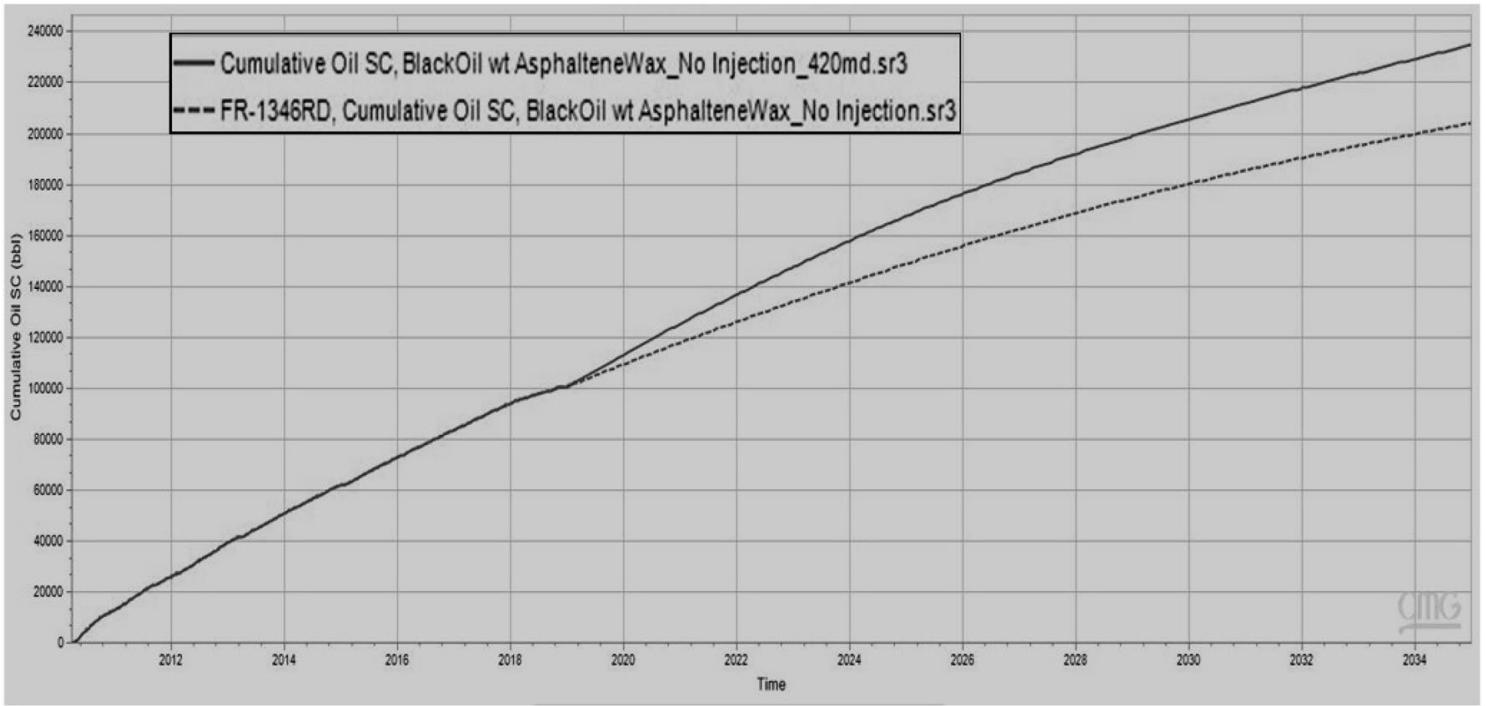

Fig. 11 Simulated cumulated oil production changes for FR 1346 RD due to increase in permeability from 300 to 420 md due to condensate treatment

Table 7 Effect of condensate treatment on cumulative oil production and recovery factors for FR 1346 RD

\begin{tabular}{lllc}
\hline Production & $\begin{array}{l}\text { Permeability, Oil, bbls } \\
\text { md }\end{array}$ & $\begin{array}{l}\text { Recovery } \\
\text { factor, \% }\end{array}$ \\
\hline Original oil in place & 300 & $1,300,000$ & - \\
Cumulative 2018 & 300 & 100,000 & 7.69 \\
Cumulative 2035 & 300 & 204,193 & 15.71 \\
Cumulative 2035 & 420 & 234,724 & 18.06 \\
\hline
\end{tabular}

that the project cost savings before taxes are approximately $\$ 12.5$ MM TT over the 16-year period.

In terms of NPV, results shown in Table 10 indicate that using a $15 \%$ for the total cost savings and incremental revenue over a 16-year period, an NPV of \$4.65 MM TT for this well. The NPV was positive from year 1 of the condensate soak since there was no additional cost for equipment (e.g. for injection needed) since it was gravity-fed 
Table 8 Calculation of total cost associated with the use of steam cleaning

\begin{tabular}{|c|c|c|c|c|c|c|}
\hline \multirow[t]{2}{*}{ Date } & \multicolumn{3}{|c|}{ Winch cost calculation } & \multicolumn{3}{|c|}{ Steam cost calculation } \\
\hline & Winch hours & Unit cost/hr & Winch cost & $\begin{array}{l}\text { Tubing } \\
\text { footage }(\mathrm{Ft})\end{array}$ & $\begin{array}{l}\text { Unit cost to } \\
\text { steam tubing/ } \\
\mathrm{Ft}\end{array}$ & Steam cleaning cost \\
\hline 2010 April & 69 & $\$ 1,000.00$ & $\$ 69,000.00$ & 2500 & $\$ 30$ & $\$ 75,000$ \\
\hline $2011 \mathrm{Jan}$ & 80.5 & $\$ 1,000.00$ & $\$ 80,500.00$ & 2500 & $\$ 30$ & $\$ 75,000$ \\
\hline 2011 Sept & 45.5 & $\$ 1,000.00$ & $\$ 45,500.00$ & 2500 & $\$ 30$ & $\$ 75,000$ \\
\hline 2012 Mar & 57.5 & $\$ 1,000.00$ & $\$ 57,500.00$ & 2500 & $\$ 30$ & $\$ 75,000$ \\
\hline 2013 Mar & 66.5 & $\$ 1,000.00$ & $\$ 66,500.00$ & 2500 & $\$ 30$ & $\$ 75,000$ \\
\hline 2015 Jan & 61 & $\$ 1,000.00$ & $\$ 61,000.00$ & 2500 & $\$ 30$ & $\$ 75,000$ \\
\hline 2016 Jan & 48.5 & $\$ 1,150.00$ & $\$ 55,775.00$ & 2500 & $\$ 30$ & $\$ 75,000$ \\
\hline 2017 Jan & 48.5 & $\$ 1,150.00$ & $\$ 55,775.00$ & 2500 & $\$ 30$ & $\$ 75,000$ \\
\hline $2018 \mathrm{Mar}$ & 33 & $\$ 1,150.00$ & $\$ 37,950.00$ & 2500 & $\$ 30$ & $\$ 75,000$ \\
\hline 2018 Sept & 80 & $\$ 1,150.00$ & $\$ 92,000.00$ & 2500 & $\$ 30$ & $\$ 75,000$ \\
\hline 2019 Feb & 8 & $\$ 1,150.00$ & $\$ 9,200.00$ & 2500 & $\$ 30$ & $\$ 75,000$ \\
\hline Subtotal cOST & - & $\$ 630,700.00$ & - & - & $\$ 825,000.00$ & - \\
\hline $\begin{array}{l}\text { TOTAL cost } \\
\text { for steam } \\
\text { cleaning for } \\
11 \text { years }\end{array}$ & \multicolumn{6}{|l|}{$\$ 1,455,700.00$} \\
\hline $\begin{array}{l}\text { TOTAL cost } \\
\text { for steam } \\
\text { cleaning for } \\
1 \text { year }\end{array}$ & $\$ 132,336.00$ & & & & & \\
\hline
\end{tabular}

Table 9 Economic evaluation associated with the use of the condensate treatment vs steam cleaning for an 16-year period

\begin{tabular}{lc}
\hline Total cost for steam cleaning for 1 year & $\$ 132,336.00$ \\
\hline Cost associated with a yearly condensate soak & $\$ 18,000$ \\
Associated yearly cost savings associated with a condensate soak & $\$ 114,336.00$ \\
Associated yearly cost savings associated with a condensate soak for 16 years & $\$ 1,829,382.00$ \\
Additional revenue associated with 30,531 barrels of oil for 16 years (\$7 TT to \$1 US & $\$ 10,685,850.00$ \\
@ 50 USD per barrel of oil) & \\
Total revenue improvement for 16 years (cost savings and additional revenue) & $\$ 12,515,232.00$ \\
Annual total revenue improvement (cost savings and additional revenue) & $\$ 782,202.00$ \\
\hline
\end{tabular}

from a tanker truck. The economic savings were due to less down time, no winch hours and no steam cleaning cost required for removing the wax from the tubing.

\section{Conclusion}

The results of this study demonstrated that the injection of produced condensate can result in a $33 \%$ increase in permeability as it behaves as a solvent facilitating dewaxing of reservoirs that are plugged with asphaltenes and waxes. Simulation studies using the FR 1346 RD test case showed similar production of cumulative oil with the condensate, nitrogen and carbon dioxide, which are the best results. Tuning of the simulator to factor the increase in permeability from 300 to 420 md due to condensate treatment demonstrated an increase in the permeability will result in an increase in the rate of production of almost $46 \%$ (24 to 35 bopd) translating in an overall gain of 30,531 bbls of oil associated with a significant financial gain of approximately \$4.7 MM TT over the 16-year period for one well. This study offers compelling evidence that the use of produced condensate in EOR is an economically and environmentally friendly strategy for EOR in Trinidad. 
Table 10 NPV economic evaluation associated with the condensate treatment

\begin{tabular}{llc}
\hline Year & $\begin{array}{l}\text { Total cost savings\&incremental revenue } \\
\text { utilizing condensate soak }\end{array}$ & $\begin{array}{l}\text { Percent value } \\
\text { using } 15 \%\end{array}$ \\
\hline 1 & 782,202 & 680,176 \\
2 & 782,202 & 591,457 \\
3 & 782,202 & 514,311 \\
4 & 782,202 & 447,227 \\
5 & 782,202 & 388,893 \\
6 & 782,202 & 338,168 \\
7 & 782,202 & 294,059 \\
8 & 782,202 & 255,703 \\
9 & 782,202 & 222,351 \\
10 & 782,202 & 193,348 \\
11 & 782,202 & 168,129 \\
12 & 782,202 & 146,199 \\
13 & 782,202 & 127,130 \\
14 & 782,202 & 110,548 \\
15 & 782,202 & 96,128 \\
16 & 782,202 & 83,590 \\
& NPV & $4,657,414$ \\
\hline
\end{tabular}

\section{Compliance with Ethical Standards}

Conflict of interest On behalf of all the co-authors, the corresponding author states that there is no conflict of interest.

Human or Animal Rights The research was conducted with Compliance with Ethical Standards and did not involve human participants and/or animals.

Funding No funding was obtained for the execution of this study.

Open Access This article is licensed under a Creative Commons Attribution 4.0 International License, which permits use, sharing, adaptation, distribution and reproduction in any medium or format, as long as you give appropriate credit to the original author(s) and the source, provide a link to the Creative Commons licence, and indicate if changes were made. The images or other third party material in this article are included in the article's Creative Commons licence, unless indicated otherwise in a credit line to the material. If material is not included in the article's Creative Commons licence and your intended use is not permitted by statutory regulation or exceeds the permitted use, you will need to obtain permission directly from the copyright holder. To view a copy of this licence, visit http://creativecommons.org/licenses/by/4.0/.
Butler RM, Jiang Q (2000) Improved Recovery of Heavy Oil by Vapex with Widely Spaced Horizontal Injectors and Producers. J Cdn Pet Tech 39(1):48-56

Cifarelli, L., Wagner, F., \& Marchionna, M. (2018). Fossil energy: From conventional oil and gas to the shale revolution. EPJ Web of Conferences, 189,N.PAG.-library.ashford.edu/https://doi. org/10.1051/epjconf/201818900004

Conrad D, Jagessar J (2018) Real Exchange Rate Misalignment and Economic Growth: The Case of Trinidad and Tobago. Economies 6:52

Hosein R, Betrand W, Dawe R (2011) Trinidad EOR 1 More than 1 Billion barrles of heavy oil remain on land. Oil Gas J 109(36):89

Ivory J, Chang J, Coates R, Forshner K (2010) Investigation of Cyclic Solvent Injection Process for Heavy Oil Recovery. J Cdn Pet Tech 49(9):22-33

Jamaloei BY, Dong M, Mahinpey N, Maini BB (2012) Enhanced Cyclic Solvent Process (ECSP) for Heavy Oil and Bitumen Recovery in Thin Reservoirs. Energy Fuels 26(5):2865-2874

Knorr, K.D. and Imran, M. (2011). Solvent Chamber Development in 3-D Physical Model Experiments of Solvent Vapour Extraction Processes (SVX) With Various Permeabilites and Solvent Vapour Qualities", Paper SPE 149190, The Canadian Unconventional Resources Conference. Calgary. 15-17.

Liu H, Cheng L, Xiong H, Huang S (2017) Effects of Solvent Properties and Injection Strategies on Solvent-Enhanced Steam Flooding for Thin Heavy Oil Reservoirs with Semi-Analytical Approach. Oil \& Gas Science and Technology - Revue d'IFP Energies nouvelles Institut Français du Pétrole. 72(4):20

Masoodi R, Pillai K (2011) A general formula for capillary suctionpressure in porous media. Journal of Porous Media 15(8):775-783.

Ministry of Energy and Energy Industries. (2019). Retrieved from Historical Facts on the Petroleum Industry of Trinidad and Tobago: http://www.energy.gov.tt/historical-facts-petroleum/

Romero-Zeron, L. (2012). Advances in Enhanced Oil Recovery Processes. www.Intechopen.com https://doi.org/10.5772/45947

Sheng, J. J. (2015). Status of Polymer-Flooding Technology. Retrieved from = onepetro-org.research.library.u.tt/download/journal-paper/ SPE-174541-PA?id=journal-paper\%2FSPE-174541-PA

Sinanan B, Evans D, Budri M (2016) SPE 180853-MS: Conceptualizing an Improved Oil Recovery Master Plan for Trinidad \& Tobago. SPE Journal. https://doi.org/10.2118/180853-MS

Taber, J. J., Martin, F. D., \& Seright, R. S. (1997). EOR Screening Criteria Revisitedd Part 1: Introduction to Screening Criteria and Enhanced Recovery Field Projects. In SPE Reservoir Engineering. Retrieved from https://www-onepetro-org.research.libra ry.u.tt/download/journal-paper/SPE-35385-PA?id=journal-paper \%2FSPE-35385-PA

Verlaan ML, Hedden R, Castellanos Díaz O, Lastovka V, Giraldo Sierra CA (2015) Solvent Enhanced Steam Drive: Experiences from the First Field Pilot in Canada. Society of Petroleum Engineers. https://doi.org/10.2118/175414-MS

Publisher's Note Springer Nature remains neutral with regard to jurisdictional claims in published maps and institutional affiliations.

\section{References}

Boswood DW, Kreh KA (2011) Fully Miscible Micellar Acidizing Solvents vs Xylene The Better Paraffin Solution. Society of Petroleum Engineers. https://doi.org/10.2118/140128-MS 